\title{
Unexpected and striking effect of heparin-free dialysis on cytokine release
}

\author{
Alicja Rydzewska-Rosolowska ${ }^{1}$ (D) Joanna Gozdzikiewicz-Lapinska ${ }^{2} \cdot$ \\ Jacek Borawski $^{1} \cdot$ Ewa Koc-Zorawska $^{2} \cdot$ Michal Mysliwiec $^{1} \cdot$ Beata Naumnik $^{1}$
}

Received: 26 February 2017 / Accepted: 9 April 2017 / Published online: 19 April 2017

(c) The Author(s) 2017. This article is an open access publication

\begin{abstract}
Heparin (both unfractionated and low molecular weight) is not only a potent anticoagulant but also has many pleiotropic effects, some of which are mediated by cytokine release. We compared the effect of hemodialysis (HD) with enoxaparin as an anticoagulant and without systemic anticoagulation (heparin-grafted membrane-Evodial) on the release of monocyte chemoattractant protein 1 (MCP-1), endostatin (ES) and activin A (Act-A). Nineteen stable HD patients were dialyzed with or without heparin, and plasma levels of MCP-1, ES and Act-A were measured after such a dialysis. During HD with Evodial, the intradialytic levels of all three cytokines were $2-3$ folds lower. The between-anticoagulant differences were significant over time for all three cytokines: MCP-1 $(P<0.001)$, ES $(P<0.001)$ and Act-A $(P<0.001)$. This striking effect of heparin-free dialysis with Evodial membrane may be beneficial not only because it reduces the possibility of bleeding complications but also because it might reduce proinflammatory cytokine concentration and therefore contribute to the improvement in endothelial function. Further studies are needed to determine whether it has a positive effect on morbidity and mortality of maintenance HD patients.
\end{abstract}

Keywords Monocyte chemoattractant protein-1 . Endostatin · Activin A · Enoxaparin · Heparin-grafted membrane $\cdot$ Hemodialysis

Alicja Rydzewska-Rosolowska

alunieczka1@wp.pl

1 I Department of Nephrology and Transplantation With Dialysis Unit, Medical University of Bialystok, Zurawia 14, 15-540, Białystok, Poland

2 II Department of Nephrology and Hypertension With Dialysis Unit, Medical University of Bialystok, Białystok, Poland

\section{Introduction}

Heparin, both unfractionated (UFH) and low molecular weight (LMWH) is not only a potent anticoagulant but also has many pleiotropic effects, some of which are mediated by cytokine release [1-3]. Hemodialysis (HD), a procedure during which heparin is routinely used, can also cause an increase in cytokine levels. Therefore, it generates an abundance of growth factors, cytokines and other mediators playing an important role in the pathogenesis of many signs, symptoms and complications of end-stage renal disease. To finally elucidate between the role of heparin and hemodialysis on cytokine profiles, aiming to prove that heparin-free dialysis does not cause cytokine release, we constructed the current study to directly compare the effect of dialysis using Evodial membranes with standard dialysis with LMWH anticoagulation. Based on our former experience, we chose to measure monocyte chemoattractant protein-1 (MCP-1), endostatin (ES) and activin A (Act-A) concentrations $[4,5]$.

Microinflammation is practically universally present in all hemodialysis patients. It results from serious disturbances of acquired immunity which are caused by many different factors. The main players are: uremia per se, medications used and the hemodialysis procedure and its complications. Antigen-presenting cells (monocytes) preactivation, overproduction of proinflammatory cytokines (Il-1, Il-6, TNF- $\alpha$ ) and deficient T lymphocyte-dependent immune response are causes of frequent infections, malnutrition-inflammation-atherosclerosis (MIA) syndrome, high failure vaccination rates among others [6].

The effect of low molecular weight heparins on the above-mentioned microinflammation is not fully understood. Most groups (including ours) report beneficial 
effects of different kinds of heparins in HD patients. However, there are some studies in other patients showing other results, e.g., an Australian group demonstrated that enoxaparin decreased by $48 \%$ and dalteparin increased by $25 \%$ the release of proinflammatory cytokines from peripheral blood mononuclear cells of asthmatics [7]. Therefore, we aimed to further elucidate the subject.

Monocyte chemoattractant protein-1 belongs to the family of chemokines-small heparin-binding proteins that regulate cell trafficking. It is produced, among others, by epithelial, endothelial, mesangial, smooth muscle cells and fibroblasts and controls the migration and infiltration of monocytes, memory $\mathrm{T}$ lymphocytes and natural killer cells. Evidence points to its major role in many human pathologies include atherosclerosis (causes plaque instability), rheumatoid arthritis and progressive renal injury in diabetic nephropathy [8]. The effect of heparin on MCP-1 is unknown as the results are conflicting [9-11].

Endostatin is a potent angiogenesis inhibitor. It is a fragment of collagen XVIIIA1-a proteoglycan containing heparan sulfate. It has a number of biological functions: It suppresses tumor cell migration and invasion, inhibits endothelial cell migration and proliferation, acts against vascular endothelial growth factor, and induces endothelial cell apoptosis and many others [12]. ES was named "resistance-free cancer therapy" and has been extensively demonstrated to inhibit tumor growth in many models with absolute lack of toxicity [13]. Its benefits were also demonstrated in other diseases, e.g., diabetic nephropathy [14]. Endostatin levels are remarkably high in HD patients and apparently not related to heparin administration [15], and in this, population may unfortunately be a marker of "defective" angiogenesis causing a higher rate of genitourinary malignancies (its levels are elevated in renal cell carcinoma and correlate with tumor aggressiveness) [16].

Activin A was discovered in the 80s as a gonadal protein. It is a pluripotent cytokine from the transforming growth factor- $\beta$ family, which takes part in organogenesis, wound healing, fibrosis, immune response, pancreatic $\beta$-cell number and function regulation. It is also proven that heparin releases Act-A during hemodialysis [4, 5].

\section{Patients and methods}

\section{Patients}

Nineteen stable, chronic hemodialysis patients participated in the study. The main exclusion criteria were: lack of consent, history of neoplasm, leukopenia, ongoing infection, trauma or surgery (up to one month before study enrollment), immunosuppressive treatment, hemodialysis vintage shorter than 3 months, lack of native arteriovenous fistula,
Table 1 Clinical characteristics of the patients

\begin{tabular}{ll}
\hline Age (years) & $57(18-81)$ \\
Sex & \\
Male $(n / \%)$ & $9 / 47.4 \%$ \\
Female $(n / \%)$ & $10 / 52.6 \%$ \\
Cause or renal disease & \\
Unknown $(n / \%)$ & $8 / 42.1 \%$ \\
Glomerulonephritis $(n / \%)$ & $4 / 21 \%$ \\
Polycystic kidney disease $(n / \%)$ & $3 / 15.7 \%$ \\
Diabetic nephropathy $(n / \%)$ & $1 / 5.3 \%$ \\
Chronic interstitial nephritis $(n / \%)$ & $1 / 5.3 \%$ \\
Hypertensive nephropathy $(n / \%)$ & $1 / 5.3 \%$ \\
Obstructive nephropathy $(n / \%)$ & $1 / 5.3 \%$ \\
Dialysis vintage (months) & $42(7-119)$ \\
Major comorbidities & \\
Hypertension & $17 / 89.4 \%$ \\
Cardiovascular disease & $6 / 31.5 \%$ \\
Diabetes & $1 / 5.3 \%$ \\
Type of dialysis membrane & \\
Polysulfone & $16 / 84.2 \%$ \\
Modified cellulose & $3 / 15.8 \%$ \\
\hline
\end{tabular}

$K t / V<1,2$, hemostatic abnormalities and oral anticoagulation. The basic clinical data are presented in Table 1.

The study was conducted according to Good Clinical Practice and in agreement with Declaration of Helsinki. The protocol was approved by local bioethics committee, and all individual participants signed informed consent before entering the study. The study was a prospective one planned initially to study the effect of heparin-free dialysis on myeloperoxidase release [17]; for this study, frozen samples were used (19 for MCP-1 and endostatin and 12 for activin A).

\section{Study design and sampling}

All participating patients were dialyzed with a stable, clinically efficient dose of enoxaparin (Clexane, Sanofi-Aventis, France), administered as a single bolus, before commencing the study (doses ranged between 20 and $60 \mathrm{mg}$ ). During the study, dialysis dose, dialyzer type (reported in Table 1) and other pharmacologic treatment remained unchanged. At least $48 \mathrm{~h}$ after a dialysis session during which enoxaparin was used, the patient was switched to dialysis without systemic anticoagulation. During this procedure, a polycarbonate hollow-fiber dialyzer with heparin-grafted membrane (Evodial, Gambro-Diaverum, Lund, Sweden) was used (the area of the dialyzer was kept constant). Before both procedures, the extracorporeal circuit was flushed with $1000 \mathrm{ml}$ of normal saline containing $2.0 \mathrm{IU} / \mathrm{ml}$ of unfractionated heparin to avoid early clotting. Blood was drawn from the arterial line before the start of dialysis procedure 
and, respectively, after 10 (T10) and $120 \mathrm{~min}$ (T120) after slowing the blood flow to $100 \mathrm{ml} / \mathrm{min}$ for $1 \mathrm{~min}$.

\section{Laboratory parameters}

Plasma levels of MCP-1, ES and Act-A were measured in duplicate, by ELISA, using commercially available kits from R\&D Systems and Oxford Bio-Innovation Ltd., respectively, according to manufacturer's instructions. For calculation of results, a computer and curve-fitting program were used. The within- and between-assay coefficients were $<8 \%$.

\section{Statistical analysis}

Data were analyzed using Stata software (version 9.2). The data distribution was normal, and one-way or twoway ANOVA were used as appropriate. For post hoc group comparisons, Bonferroni correction was used. All statistical tests were two-sided, and $P<0.05$ was considered significant.

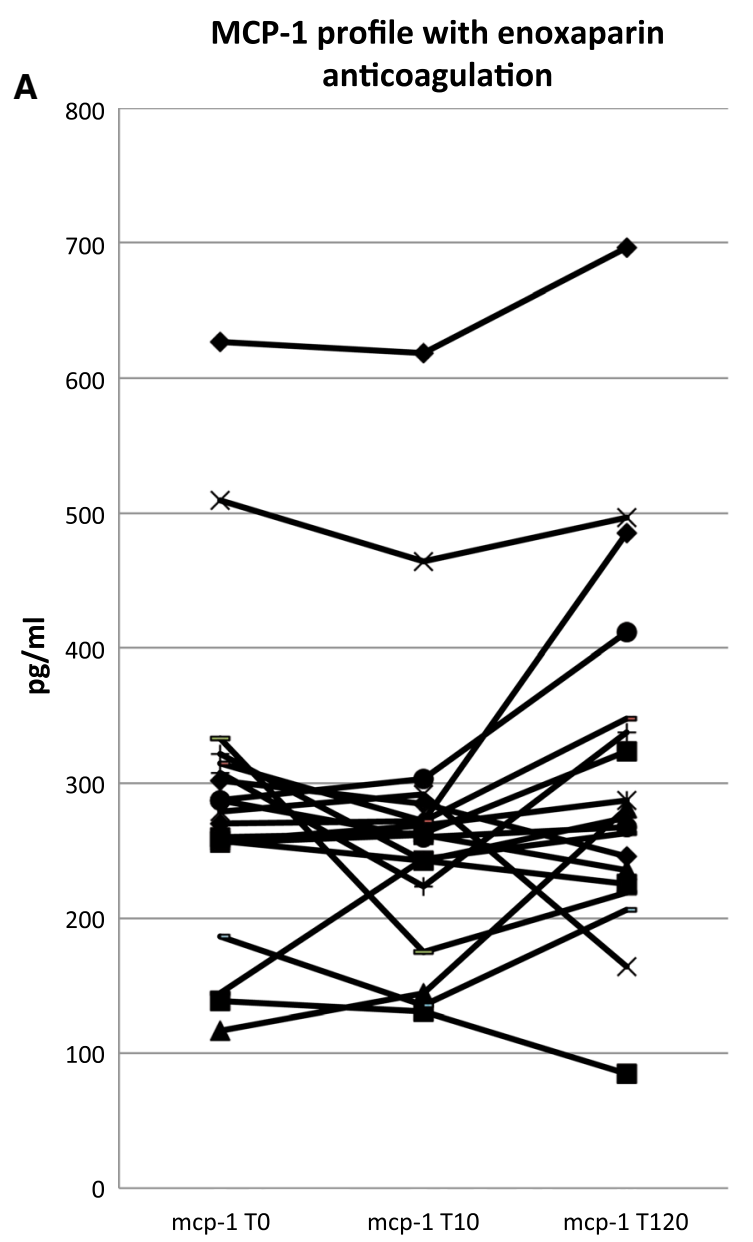

\section{Results}

During standard dialysis with enoxaparin plasma, MCP-1 levels remained stable $\left(\chi^{2}=0.792, P=0.613\right.$, Fig. 1a). Pre-dialysis, they were $287.1 \mathrm{pg} / \mathrm{ml}$ (sd 119.1), at T10 $268.1 \mathrm{pg} / \mathrm{ml}$ (sd 112.5) and at T120 $307.9 \mathrm{pg} / \mathrm{ml}(\mathrm{sd}$ 137.9).

Plasma levels of ES also remained constant during the entire procedure $\left(\chi^{2}=0.013, P=0.239\right.$, Fig. $\left.2 \mathrm{a}\right)$. They were $898.1 \mathrm{ng} / \mathrm{ml}(\mathrm{sd} \mathrm{174.8)}$ ) at T0, $832.3 \mathrm{ng} / \mathrm{ml}(\mathrm{sd}$ 172.9) at T10 and 804.6 (sd 170.1) at T120.

Act-A levels changed remarkably over time $\left(\chi^{2}=7.724, P<0.001\right.$, Fig. 3a). Before the start of hemodialysis, the mean level was $797.7 \mathrm{pg} / \mathrm{ml}$ (sd 325.9), and then, it increased abruptly (in all patients) to a mean of $3596.8 \mathrm{pg} / \mathrm{ml}$ ( $\mathrm{sd} \mathrm{849.1)}(P<0.001)$. After $120 \mathrm{~min}$, it remained elevated $(P=0.07)$ with a mean level of $1443.3 \mathrm{pg} / \mathrm{ml}$ (sd 613.2).

The most striking changes were seen with Evodial dialysis. Pre-dialysis values of all three cytokines were

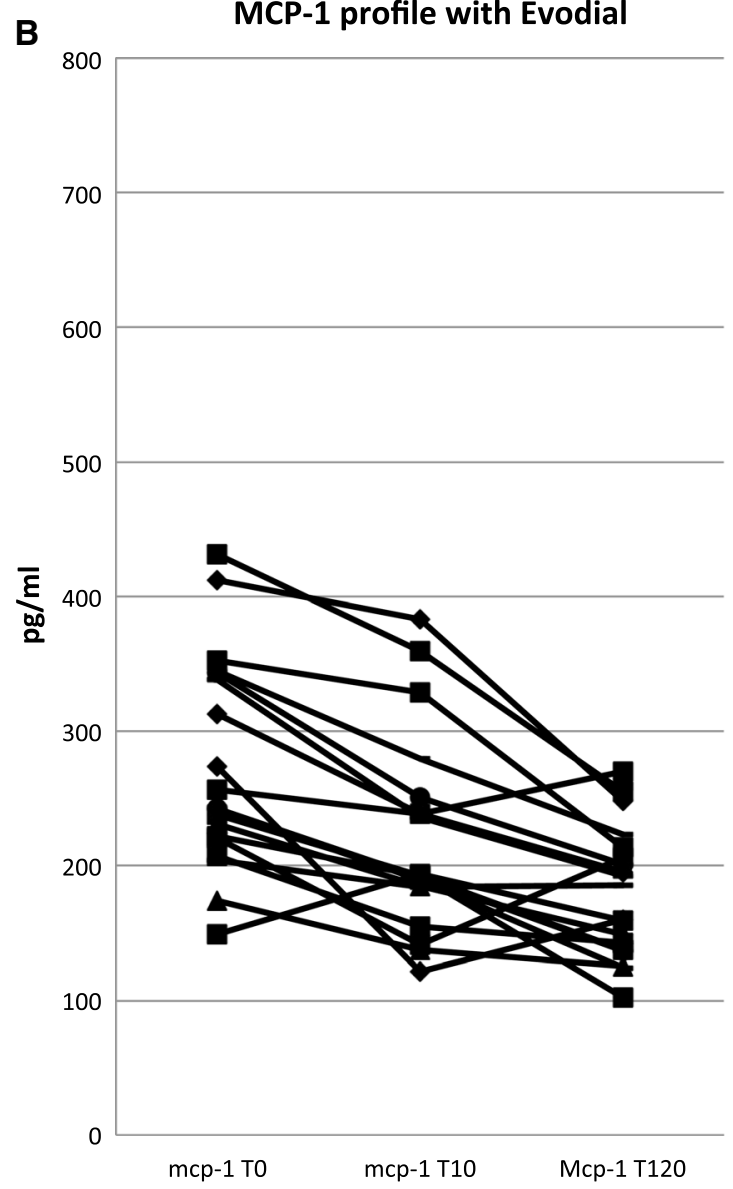

Fig. 1 MCP-1 profiles during enoxaparin and Evodial dialysis 

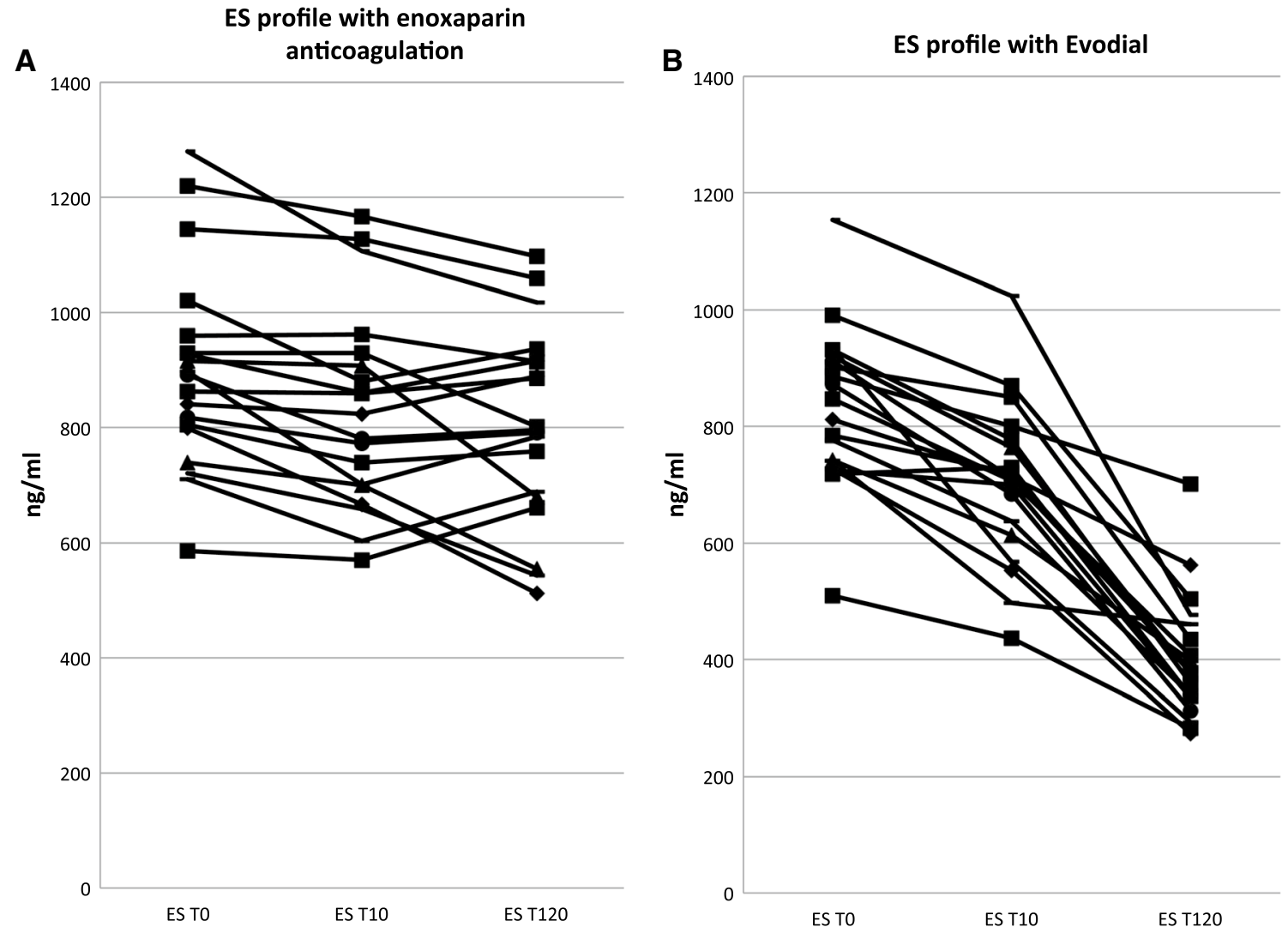

Fig. 2 ES profiles during enoxaparin and Evodial dialysis
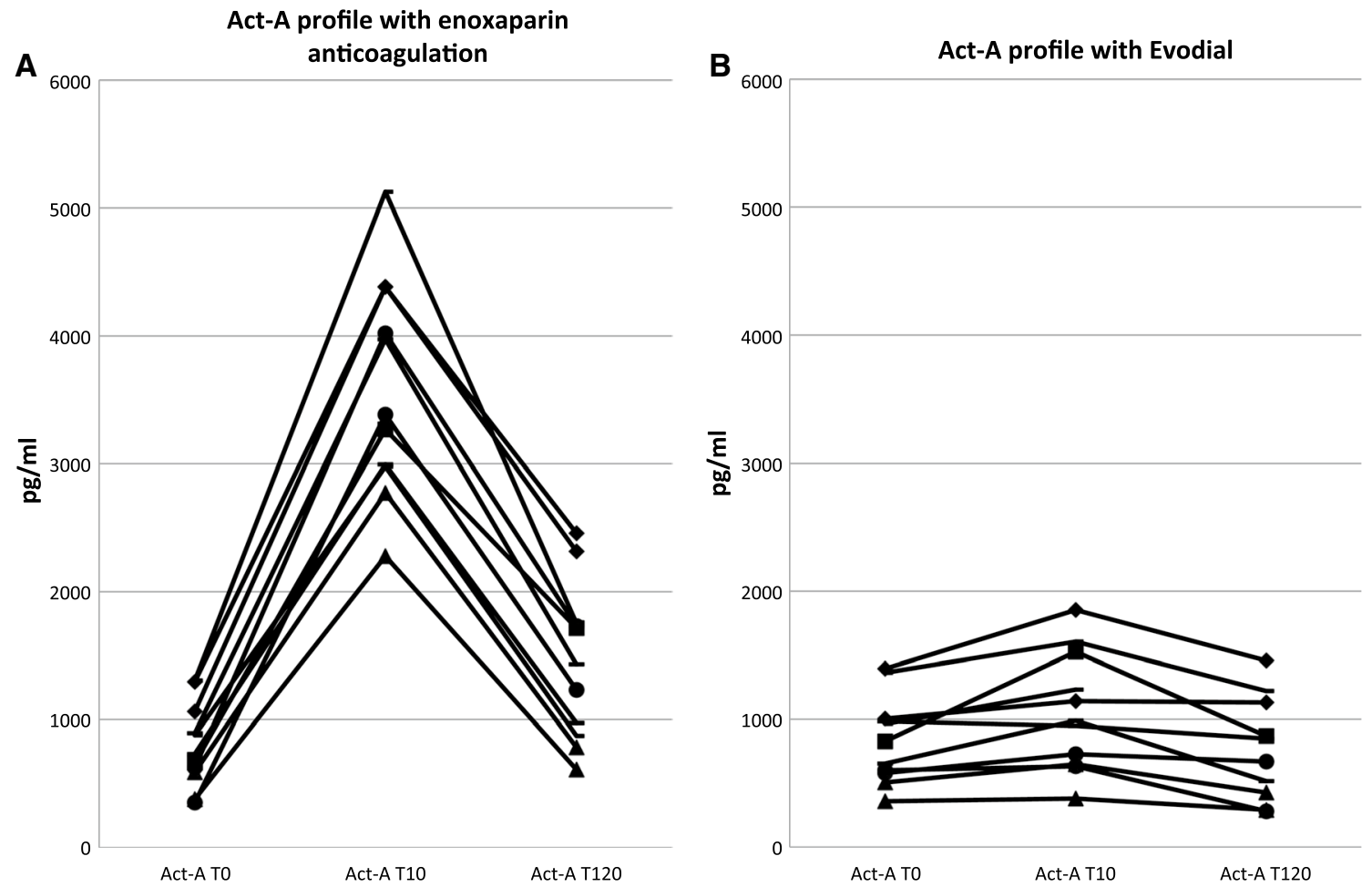

Fig. 3 Act-A profiles during enoxaparin and Evodial dialysis 
comparable. MCP-1 decreased over time $\left(\chi^{2}=4.394\right.$, $P<0.001$, Fig. 1b) from $273.5 \mathrm{pg} / \mathrm{ml}$ (sd 78.7) to $220.9 \mathrm{pg} / \mathrm{ml}(\mathrm{sd} 73.3)$ at $\mathrm{T} 10(P=0.063)$ and $180.4 \mathrm{pg} /$ $\mathrm{ml}(\mathrm{sd} 48.2)$ at $\mathrm{T} 120(P<0.001)$.

ES decreased from $835.9 \mathrm{ng} / \mathrm{ml}$ (sd 136.1) at T0 to 703.0 $($ sd 137.4) at $\mathrm{T} 10(P=0.007)$ and $400.5($ sd 105.9$)$ at $\mathrm{T} 120$ $(P<0.001)$. The changes were statistically significant $\left(\chi^{2}=1.435, P<0.001\right.$, Fig. $\left.2 b\right)$.

Act-A levels, contrary to enoxaparin dialysis, remained constant over time $\left(\chi^{2}=0.889, P=0.241\right.$, Fig. $\left.3 b\right)$ at $838.9 \mathrm{pg} / \mathrm{ml}$ (sd 338.9) pre-dialysis, $1060.5 \mathrm{pg} / \mathrm{ml} \mathrm{(sd}$ 460.8) after $10 \mathrm{~min}(P=0.629)$ and $770.5 \mathrm{pg} / \mathrm{ml}(\mathrm{sd} 405.9)$ after $120 \min (P=1.00)$.

The between-anticoagulant differences were significant over time for all three cytokines: MCP-1 $(P<0.001)$, ES $(P<0.001)$ and Act-A $(P<0.001)$.

\section{Discussion}

Our study reports unexpected depletion of plasma levels of MCP-1, endostatin and activin A during heparin-free systemic hemodialysis when compared to standard dialysis with low molecular weight heparin (in this case enoxaparin). The effect of Evodial membranes on ES and Act-A was to our knowledge not reported before, and the effect on MCP-1 is consistent with data published by Morena et al. [18].

MCP-1 levels during dialysis remained stable in our study, although there was a tendency to their intradialytic lowering (after $10 \mathrm{~min}$ ) with a subsequent rise at $120 \mathrm{~min}$. This is in agreement with our previous study [11]; most papers report a stable or slightly increased levels [18-20] attributing the effect to dialysis itself (inadequate clearance or enhanced synthesis and release) rather than heparin used. It is widely believed that MCP-1 is a marker of biocompatibility and that its increased levels contribute to inflammation, dyslipidemia and atherosclerosis - the main burden of end-stage renal disease patients. The potential of Evodial for lowering circulating MCP-1 levels could have beneficial effects on these conditions. The probable mechanism is adsorption of MCP-1 onto the heparin-grafted membranes. In our study, during Evodial dialysis, heparin was used only for pre-rinsing (in contrast to the study by Morena and co-workers who used either a 100 or $30 \%$ dose of heparin during Evodial dialysis), and therefore, it could not contribute to the release of MCP-1.

ES levels were, as reported before [15], extremely high in our patients and did not change after heparin administration. As was the case with MCP-1 levels, they decreased dramatically during Evodial dialysis. The phenomenon of very high endostatin levels in kidney impairment is intriguing. On one side, it could suggest an antitumor activity, and on the other, a much probable theory is that it reflects defective angiogenesis, may be a cause for defective collateral vessel formation and contribute to the higher rate of genitourinary tract malignancies observed in HD patients [21]. ES levels are also increased in patients with renal cell carcinoma [16]. Therefore, the potential benefit of lowering endostatin levels during hemodialysis could be of paramount importance for these patients.

The effect of heparins (both UFH and LMWH) on Act-A has been studied extensively by our group and others [4, 5]. The mechanisms mediating this phenomenon are probably displacement from cell surface proteoglycans [22] and dissolution of the complex [23]. As bioactive activin A is detected in atherosclerotic plaques, it causes smooth muscle cell proliferation and differentiation of monocytes into macrophages and probably promotes the development of atherosclerosis [24]. It also plays an important role in modulating the immune system controlling the release of other proinflammatory cytokines; therefore, blocking its actions may be of therapeutic interest in inflammatory conditions [25]. Heparin-free dialysis prevented activin A release mediated by enoxaparin and stabilized its levels.

Other cytokines studied during Evodial dialysis were interleukin 6 (Il-6), tumor necrosis factor- $\alpha$ (TNF- $\alpha)$ [18] and myeloperoxidase (MPO) [17]. Il-6 and TNF- $\alpha$ levels remained stable during dialysis, but MPO levels were significantly lower. This suggests that heparin-grafted membrane has a potential of binding other cytokines as well and it is not a solitary phenomenon. Further studies are needed to elucidate the role of this membrane, as it is also possible that it will bind some anti-inflammatory cytokines.

We are of course aware of the limitations of our study, mainly the small number of patients, although since they served as their own controls it could be minimized. The other limitation would be that only one dialysis with Evodial was performed, but since the effect was abrupt and already seen after $10 \mathrm{~min}$ of procedure we believe there was no carry-over effect or it was minimal. It is also unknown what happens to cytokine levels after the end of dialysis treatment, but because this procedure is carried out three times weekly one can speculate that cytokine depletion is of clinical importance. Last but not least, we did not study other proinflammatory cytokines, and obviously, decreased levels of those cytokines do not necessarily imply "less" inflammation, but the notion is intriguing and definitely requires more research.

In conclusion, heparin-free dialysis with Evodial membrane may be beneficial not only because it reduces the possibility of bleeding complications, but also because it might reduce the level of proinflammatory cytokines and therefore contribute to the improvement in endothelial function. Further studies are needed to determine whether it has a positive effect on morbidity and mortality of maintenance hemodialysis patients. 


\section{Compliance with ethical standards}

Conflict of interest On behalf of all authors, the corresponding author states that there is no conflict of interest.

Informed consent Informed consent was obtained from all individual participants included in the study.

Human and animal rights All procedures performed in studies involving human participants were in accordance with the ethical standards of the institutional and/or national research committee and with the 1964 Helsinki declaration and its later amendments or comparable ethical standards.

Open Access This article is distributed under the terms of the Creative Commons Attribution 4.0 International License (http://creativecommons.org/licenses/by/4.0/), which permits unrestricted use, distribution, and reproduction in any medium, provided you give appropriate credit to the original author(s) and the source, provide a link to the Creative Commons license, and indicate if changes were made.

\section{References}

1. Fareed J, Hoppensteadt DA (2000) Heparins in the new millennium: will unfractionated heparin survive? Epilogue. Semin Thromb Hemost 26(Suppl 1):87-88

2. Fareed J, Hoppensteadt DA, Bick RL (2000) An update on heparins at the beginning of the new millennium. Semin Thromb Hemost 26(Suppl 1):5-21

3. Presta M, Leali D, Stabile H, Ronca R, Camozzi M, Coco L, Moroni E, Liekens S, Rusnati M (2003) Heparin derivatives as angiogenesis inhibitors. Curr Pharm Des 9(7):553-566

4. Borawski J, Naumnik B, Mysliwiec M (2003) Activation of hepatocyte growth factor/activin A/follistatin system during hemodialysis: role of heparin. Kidney Int 64(6):2229-2237. doi:10.1046/j.1523-1755.2003.00307.x

5. Rydzewska-Rosolowska A, Borawski J, Mysliwiec M (2009) Hepatocyte growth factor/activin A/follistatin system activation during hemodialysis with different low molecular weight heparins. Ren Fail 31(9):791-797. doi:10.3109/08860220903180608

6. Eleftheriadis T, Antoniadi G, Liakopoulos V, Kartsios C, Stefanidis I (2007) Disturbances of acquired immunity in hemodialysis patients. Semin Dial 20(5):440-451. doi:10.1111/j.1525-139X.2007.00283.x

7. Shastri MD, Stewart N, Eapen M, Peterson GM, Zaidi ST, Gueven N, Sohal SS, Patel RP (2015) Opposing effects of low molecular weight heparins on the release of inflammatory cytokines from peripheral blood mononuclear cells of asthmatics. PLoS ONE 10(3):e0118798. doi:10.1371/journal.pone.0118798

8. Deshmane SL, Kremlev S, Amini S, Sawaya BE (2009) Monocyte chemoattractant protein-1 (MCP-1): an overview. J Interferon Cytokine Res 29(6):313-326. doi:10.1089/jir.2008.0027

9. Akahoshi T, Kobayashi N, Hosaka S, Sekiyama N, Wada C, Kondo H (1995) In-vivo induction of monocyte chemotactic and activating factor in patients with chronic renal failure. Nephrol Dial Transplant 10(12):2244-2249

10. Jacobson SH, Egberg N, Hylander B, Lundahl J (2002) Correlation between soluble markers of endothelial dysfunction in patients with renal failure. Am J Nephrol 22(1):42-47. doi:10.1159/000046673
11. Rydzewska-Rosolowska A, Borawski J, Mysliwiec M (2009) Enoxaparin decreases serum MCP-1 concentration during haemodialysis-preliminary report. NDT Plus 2(5):429-430. doi:10.1093/ ndtplus/sfp060

12. O'Reilly MS, Boehm T, Shing Y, Fukai N, Vasios G, Lane WS, Flynn E, Birkhead JR, Olsen BR, Folkman J (1997) Endostatin: an endogenous inhibitor of angiogenesis and tumor growth. Cell 88(2):277-285. doi:10.1016/S0092-8674(00)81848-6

13. Boehm T, Folkman J, Browder T, O'Reilly MS (1997) Antiangiogenic therapy of experimental cancer does not induce acquired drug resistance. Nature 390(6658):404-407. doi:10.1038/37126

14. Ichinose K, Maeshima Y, Yamamoto Y, Kitayama H, Takazawa Y, Hirokoshi K, Sugiyama H, Yamasaki Y, Eguchi K, Makino H (2005) Antiangiogenic endostatin peptide ameliorates renal alterations in the early stage of a type 1 diabetic nephropathy model. Diabetes 54(10):2891-2903. doi:10.2337/diabetes.54.10.2891

15. Rydzewska-Rosolowska A, Borawski J, Mysliwiec M (2009) High plasma endostatin level unaffected by low-molecular weight heparin in hemodialysis patients-a preliminary report. Adv Med Sci 54(2):199-202. doi:10.2478/v10039-009-0030-7

16. Feldman AL, Alexander HR Jr, Yang JC, Linehan WM, Eyler RA, Miller MS, Steinberg SM, Libutti SK (2002) Prospective analysis of circulating endostatin levels in patients with renal cell carcinoma. Cancer 95(8):1637-1643. doi:10.1002/cncr.10845

17. Gozdzikiewicz J, Borawski J, Koc-Zorawska E, Mysliwiec M (2014) Effects of enoxaparin on myeloperoxidase release during hemodialysis. Hemodial Int 18(4):819-824. doi:10.1111/hdi.12177

18. Morena M, Jaussent I, Chalabi L, Bargnoux AS, Dupuy AM, Badiou S, Rakic C, Thomas M, Canaud B, Cristol JP, Michel F (2010) Biocompatibility of heparin-grafted hemodialysis membranes: impact on monocyte chemoattractant protein-1 circulating level and oxidative status. Hemodial Int 14(4):403-410. doi:10.1111/j.1542-4758.2010.00494.x

19. Naumnik B, Koc-Zorawska E, Mysliwiec M (2013) Over-dialysis plasma RANTES increase depends on heparin dose and cardiovascular disease status. Adv Med Sci 58(2):311-319. doi:10.2478/ ams-2013-0008

20. Papayianni A, Alexopoulos E, Giamalis P, Gionanlis L, Belechri AM, Koukoudis P, Memmos D (2002) Circulating levels of ICAM1, VCAM-1, and MCP-1 are increased in haemodialysis patients: association with inflammation, dyslipidaemia, and vascular events. Nephrol Dial Transplant 17(3):435-441

21. Mandayam S, Shahinian VB (2008) Are chronic dialysis patients at increased risk for cancer? J Nephrol 21(2):166-174

22. Hashimoto O, Nakamura T, Shoji H, Shimasaki S, Hayashi Y, Sugino H (1997) A novel role of follistatin, an activin-binding protein, in the inhibition of activin action in rat pituitary cells. Endocytotic degradation of activin and its acceleration by follistatin associated with cell-surface heparan sulfate. J Biol Chem 272(21):13835-13842

23. Sumitomo S, Inouye S, Liu XJ, Ling N, Shimasaki S (1995) The heparin binding site of follistatin is involved in its interaction with activin. Biochem Biophys Res Commun 208(1):1-9. doi:10.1006/ bbrc.1995.1297

24. Molloy CJ, Taylor DS, Pawlowski JE (1999) Novel cardiovascular actions of the activins. J Endocrinol 161(2):179-185. doi:10.1677/ joe. 0.1610179

25. Jones KL, Mansell A, Patella S, Scott BJ, Hedger MP, de Kretser DM, Phillips DJ (2007) Activin A is a critical component of the inflammatory response, and its binding protein, follistatin, reduces mortality in endotoxemia. Proc Natl Acad Sci USA 104(41):16239-16244. doi:10.1073/pnas.0705971104 